Corrigendum

\title{
Corrigendum to "Meta-Analysis of the Relationship between Deep Brain Stimulation in Patients with Parkinson's Disease and Performance in Evaluation Tests for Executive Brain Functions"
}

\author{
A. M. Martínez-Martínez, ${ }^{1}$ O. M. Aguilar, ${ }^{1,2}$ and C. A. Acevedo-Triana ${ }^{1}{ }^{1}$ \\ ${ }^{1}$ Department of Psychology, Pontificia Universidad Javeriana, Bogotá, Colombia \\ ${ }^{2}$ Department of Brain Repair and Rehabilitation, University College London, London, UK
}

Correspondence should be addressed to C. A. Acevedo-Triana; cesar.acevedo02@uptc.edu.co

Received 16 May 2018; Accepted 22 May 2018; Published 28 June 2018

Copyright (C) 2018 A. M. Martínez-Martínez et al. This is an open access article distributed under the Creative Commons Attribution License, which permits unrestricted use, distribution, and reproduction in any medium, provided the original work is properly cited.

In the article titled "Meta-Analysis of the Relationship between Deep Brain Stimulation in Patients with Parkinson's Disease and Performance in Evaluation Tests for Executive Brain Functions" [1], the first affiliation should have been linked to the second author. The revised authors' list and affiliations are shown above.

\section{References}

[1] A. M. Martínez-Martínez, O. M. Aguilar, and C. A. AcevedoTriana, "Meta-analysis of the relationship between deep brain stimulation in patients with Parkinson's disease and performance in evaluation tests for executive brain functions," Parkinson's Disease, vol. 2017, Article ID 9641392, 16 pages, 2017. 


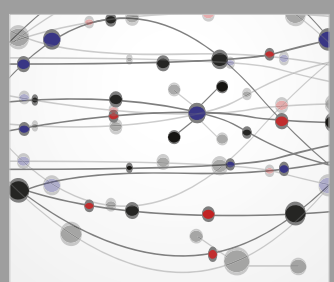

The Scientific World Journal
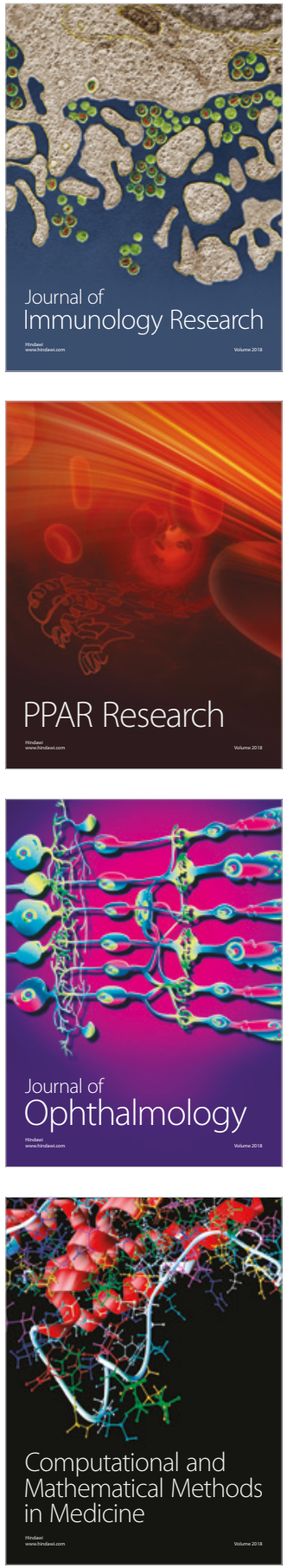

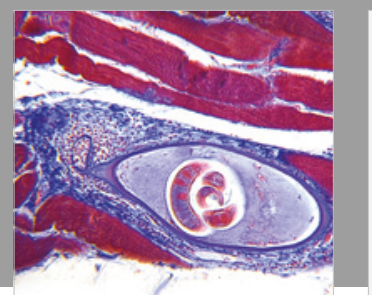

Gastroenterology Research and Practice

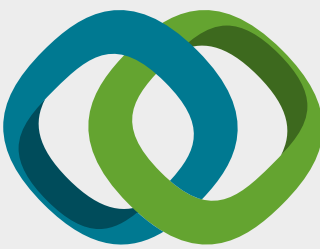

\section{Hindawi}

Submit your manuscripts at

www.hindawi.com
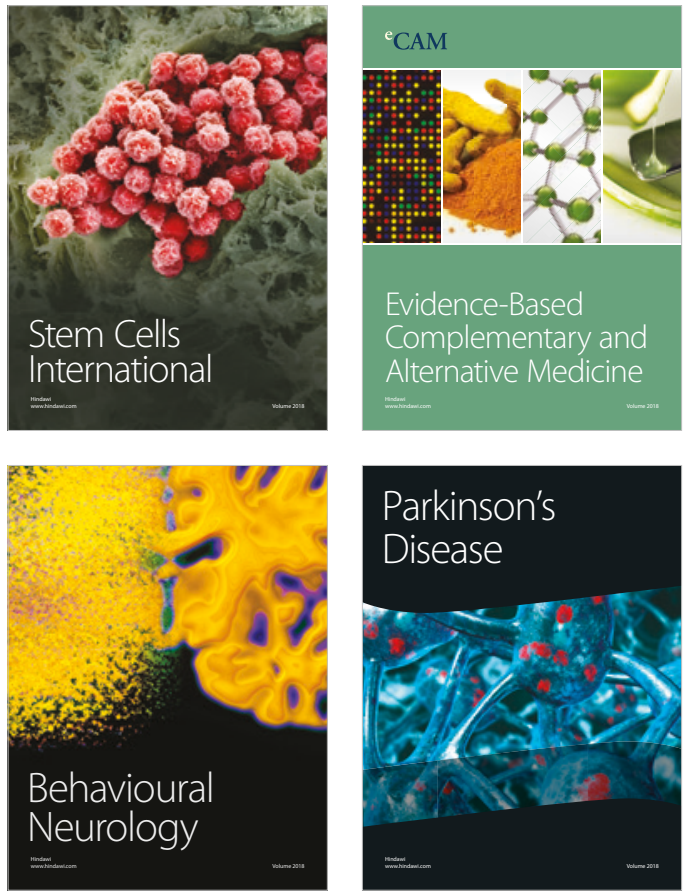

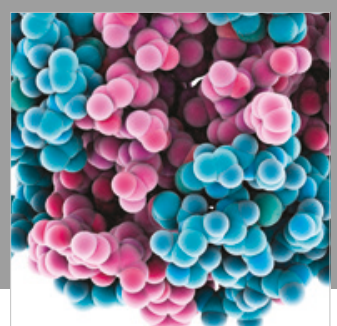

ournal of

Diabetes Research

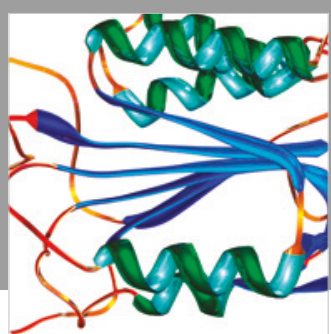

Disease Markers
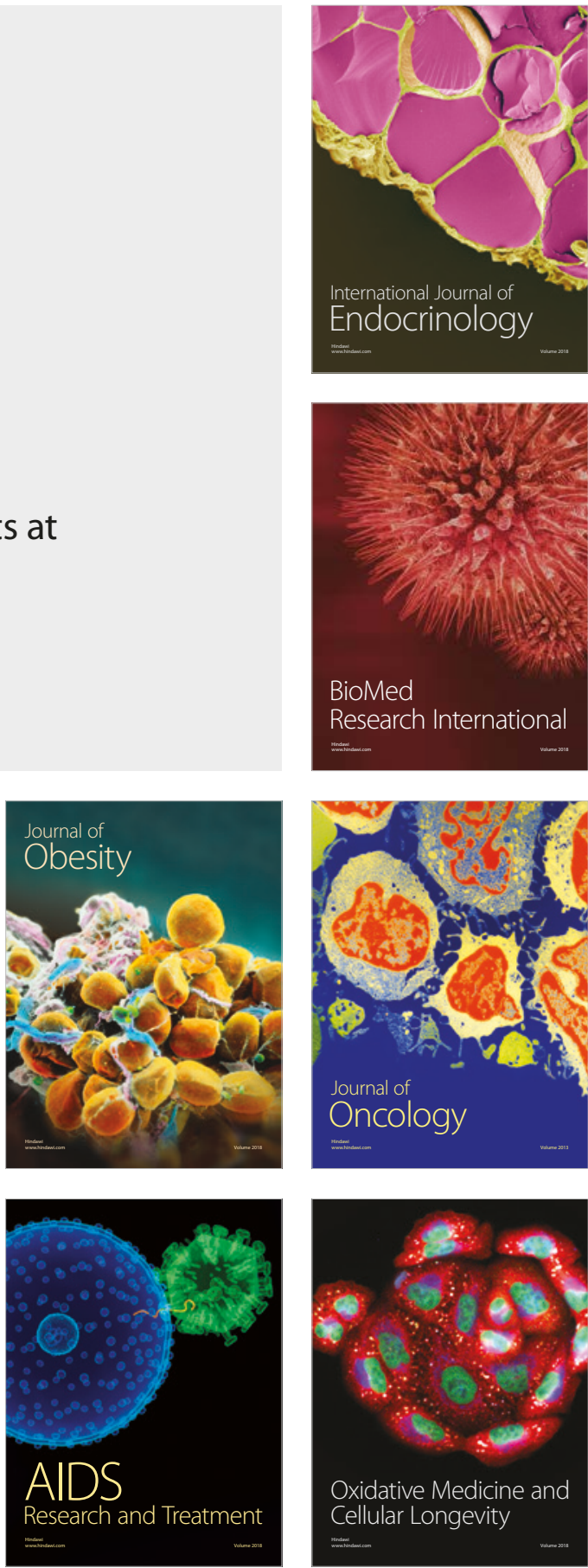